\title{
Posterior Correction of Adolescent Idiopathic Scoliosis with High-Density Pedicle Screw-Only Constructs: 5 Years of Follow-Up
}

\author{
Chang Ju Hwang ${ }^{1}$, Jong-Min Baik², Jae Hwan Cho ${ }^{1}$, So Jeong Yoon ${ }^{1}$, Dong-Ho Lee ${ }^{1}$, and Choon Sung Lee \\ ${ }^{1}$ Scoliosis Center, Asan Medical Center, Ulsan University College of Medicine, Seoul; \\ ${ }^{2}$ Department of Orthopedic Surgery, Gil Medical Center, Gachon University College of Medicine, Incheon, Korea .
}

\begin{abstract}
Purpose: This study aimed to analyze radiological outcomes in patients with adolescent idiopathic scoliosis (AIS) who underwent posterior correction with high-density pedicle screw-only constructs. We hypothesized that high-density pedicle screw-only constructs in AIS would provide a high correction rate and would facilitate the maintenance of the correction or obviate the loss thereof. Materials and Methods: We retrospectively analyzed radiological outcomes over a minimum follow-up period of 5 years in patients with AIS who underwent posterior correction with high-density pedicle screw-only constructs. A total of 124 consecutive patients were included. Demographic data, including age, sex, operated fusion level, numbers of screw, Lenke curve type, Risser stage, and follow-up period were retrospectively collected from electronic medical records and radiological measurements including serial follow-up.

Results: The average number of pedicle screws was 1.96/vertebra. The average curve correction was $48.3 \%$ for the proximal thoracic (PT) curve, $83.1 \%$ for the main thoracic (MT) curve, and $80.2 \%$ for the thoracolumbar/lumbar (TL/L) curve at final followup. Use of high-density pedicle screw-only constructs helped achieve excellent correction rates, with no significant loss of correction at final follow-up.

Conclusion: We obtained excellent correction rates of $48.3 \%$ for PT, $83.1 \%$ for MT, and $80.2 \%$ for TL/L curves using high-density pedicle screw-only constructs in AIS, with no significant loss of correction at final follow-up.
\end{abstract}

Key Words: Adolescent idiopathic scoliosis, pedicle screw, high-density, posterior-only surgery

\section{INTRODUCTION}

Posterior instrumentation with pedicle screw fixation is the current standard of care for adolescent idiopathic scoliosis (AIS). ${ }^{1}$ In 1995, Suk, et al. ${ }^{2}$ reported the radiological outcomes of 78 patients and noted improved coronal balance and less

Received: March 26, 2019 Revised: December 2, 2019

Accepted: December 23, 2019

Corresponding author: Jong-Min Baik, MD, Department of Orthopedic Surgery, Gil Medical Center, Gachon University College of Medicine, 21 Namdong-daero 774beon-gil, Namdong-gu, Incheon 21565, Korea.

Tel: 82-32-460-3384, Fax: 82-32-423-3384, E-mail: bbaik98@gmail.com

-The authors have no potential conflicts of interest to disclose.

(C) Copyright: Yonsei University College of Medicine 2020

This is an Open Access article distributed under the terms of the Creative Commons Attribution Non-Commercial License (https://creativecommons.org/licenses/ by-nc/4.0) which permits unrestricted non-commercial use, distribution, and reproduction in any medium, provided the original work is properly cited. correction loss at 2 years with screws than with hybrid constructs. Since then, application of pedicle screws to the thoracic spine has become popular in the surgical management of AIS. In 2004, Shufflebarger, et al. ${ }^{3}$ also reported that using a wide posterior release and posterior pedicle screws to correct lumbar and thoracolumbar AIS resulted in a coronal correction of $80 \%$ with good sagittal alignment at 2 years after surgery. Several studies that compared anterior spinal instrumentation with pedicle screw instrumentation for the treatment of thoracolumbar or lumbar AIS showed no statistical difference in coronal or sagittal curve correction at 2 years after surgery. ${ }^{4-6}$ Correction with posterior screw fixation helps in multidimensional spinal correction. ${ }^{7}$

Although posterior correction with pedicle screws is known to be an important and useful surgical technique in the treatment of AIS, controversy exists on the optimal density of the screws and on the resulting amount of correction, loss of cor- 
rection, and changes in distal adjacent segments. As the number of pedicle screws increases, the amount of force applied to correct the deformity can also be greater. Although the average major curve correction was reported to be approximately $50-60 \%,{ }^{8,9}$ little information is available about the relationship between pedicle screw density and correction rates of AIS. ${ }^{10}$

The purpose of this study was to analyze radiological outcomes in patients with AIS who underwent posterior correction with high-density pedicle screw-only constructs. We hypothesized that high-density pedicle screw-only constructs in AIS would provide a high correction rate and would facilitate the maintenance of the correction or obviate the loss thereof.

\section{MATERIALS AND METHODS}

After obtaining Institutional Review Board approval (Asan Medical Center, IRB No: 2017-0894), we conducted a retrospective review of all patients who underwent posterior correction and fusion with high-density pedicle screw-only constructs at our institution with a minimum follow-up of 5 years. The inclusion criteria were as follows: 1) AIS diagnosis; 2) posterior-only surgery with all pedicle screw constructs; 3 ) number of pedicle screws per one vertebra $\geq 1.6$; and 4 ) $\geq 5$ years follow-up. Patients who underwent additional anterior release surgery or thoracotomy procedures were excluded. We also excluded patients with other specific etiologies of scoliosis, including congenital scoliosis, neuromuscular scoliosis, and various syndromes.

A total of 463 consecutive patients underwent correction surgery using high-density pedicle screws for AIS between January 2002 and December 2011. Twenty-two patients were excluded because they underwent anterior release, and follow-up data for $\geq 5$ years were not available for 317 patients. Therefore, 124 patients who underwent posterior-only surgery with all pedicle screw constructs were finally included. Demographic data, including age, sex, fusion level, number of screws, Lenke curve type, Risser stage, and follow-up period, were retrospectively collected from electronic medical records.

\section{Radiological measurements}

Radiological data were obtained from the picture archiving communication system of our institution. Radiological parameters were measured in whole-spine standing anteroposterior and lateral radiographs taken preoperatively in the standing position with full extended arms and straight gaze, and all patients were positioned uniformly in this posture in postoperative, 2-year follow-up, and 5-year follow-up time points. The following factors were measured: proximal thoracic (PT), main thoracic (MT), and thoracolumbar/lumbar (TL/L) Cobb angles; percentage of flexibility; distance between the $\mathrm{C} 7$ plumb line and the center sacral vertical line (C7-CSVL); distance between the center of the last instrumented vertebra and
CSVL (LIV-CSVL); sagittal vertical axis (SVA); thoracic kyphosis (TK); and lumbar lordosis (LL). Flexibility was measured on preoperative passive side-bending radiographs, and flexibility rate (FR) was calculated using the following formula: FR (\%) = [(upright angle - side-bending angle)/upright angle $] \times 100 .{ }^{11}$ The average curve correction was calculated using the following formula: average curve correction (\%) = [(average preoperative coronal Cobb angle - average postoperative coronal Cobb angle)/average preoperative coronal Cobb angle] $\times 100$. The SVA was defined as the horizontal distance from the plumb line falling from the center of $\mathrm{C} 7$ to the posterosuperior corner of S1. TK was measured between the upper endplate of T5 and the lower endplate of T12, and LL was measured between the upper endplate of $\mathrm{Ll}$ and the upper endplate of $\mathrm{S}$.

Additionally, the shoulder height difference (SHD), apical vertebral rotation (AVR), apical vertebral translation (AVT), lowest instrumented vertebral tilt (LIVT), and distal adjacent disc wedging (ADW) were measured. SHD was defined as the difference in height between the upper margins of both acromioclavicular joints and was deemed positive when the right was higher than the left acromioclavicular joint. AVR was graded using the Nash-Moe method: grade 0 , neutral position (no rotation); grade 1 , the pedicle in the concave side (the right side) starts disappearing; grade 2, the pedicle disappears; grade 3 , the contralateral pedicle (pedicle in the convex side) is in the midline of the vertebra; and grade 4 , the contralateral pedicle crosses the midline of the vertebra. ${ }^{12}$ AVT was assessed according to the distance of the center of the apical vertebra to the CSVL. LIVT was the angle between the lower endplate of the LIV and the horizontal line. ADW was defined as the angle between the lower endplate of the distal adjacent vertebra and the horizontal line. LIVT and ADW were deemed positive when the tilt faced the convex side of the instrumented thoracic curve.

\section{Surgical technique}

All patients underwent posterior surgery with the rod derotation method with pedicle screw fixation: all surgeries were performed by a single surgeon (C.S.L.). ${ }^{13}$ The patient was positioned prone with both hips and knees at $20^{\circ}$ flexion on a table (Jackson Spinal Table System, OSI, Union City, CA, USA) compatible for a $\mathrm{C}$-arm fluoroscope. After posterior exposure of the spine, the $\mathrm{C}$-arm fluoroscope was set up to obtain a posteroanterior image. Once the $\mathrm{C}$-arm fluoroscope was positioned at the target vertebra, the $\mathrm{C}$-arm was gradually rotated until a true posteroanterior view of the rotated vertebral body was acquired and both pedicles were symmetrically visualized en face. Data from thin-sectioned CT scans including the approximate rotation angle of each vertebra served as references. Pedicle screws were placed after obtaining symmetric pedicle images. At each level, screws were first placed on the concave side of where the operator stood. On the basis of the round pedicle outline on the $\mathrm{C}$-arm image, the entry points were determined at 10 o'clock and 2 o'clock positions on the 
right and left pedicles.

Preoperative CT scans were performed for all patients, and the $\mathrm{C}$-arm was used for the placement of each pedicle screw. Screws were placed in all pedicles if possible. A titanium alloy implant system (4.5, 5.5, and $6.5 \mathrm{~mm}$ in diameter) was used for all patients, and $5.5 \mathrm{~mm}$ cobalt-chrome alloy rods system were used for the assembly.

Fusion level selection was based on the classification criteria proposed by King, et al. ${ }^{14}$ and Lenke, et al. ${ }^{15}$ Although definite guidelines for the determination of the upper and lower instrumented vertebrae have not yet been established, we have published a review article on five major controversial issues regarding fusion level selection in corrective surgery for AIS. ${ }^{16}$

\section{Statistical analysis}

Data management and statistical analyses were performed with the Statistical Package for the Social Sciences (version 18.0; SPSS Inc., Chicago, IL, USA). Descriptive statistical data are reported as means, ranges, and standard deviations where appropriate. All longitudinal analyses for variables that were measured at more than two time points were performed with mixedmodel one-way analyses of variance with available data from each patient. A value of $p<0.05$ was considered statistically significant.

\section{RESULTS}

A total of 124 patients (98 females and 26 males, $79 \%$ females), with a minimum follow-up of 5 years (mean $6.15 \pm 1.63$ years), were examined. The mean patient age was 15.48 years (185.7 \pm 39.4 months). The average Risser grade was $2.83 \pm 1$.33. The demographic data of patients are described in Table 1. Most of the patients had Lenke type 1 curves $(48,38.7 \%)$, whereas 24 (19.4\%) had Lenke type 2, 19 had Lenke type 3, 19 had Lenke type 5, 7 had Lenke type 4, and 7 had Lenke type 6 curves (Table 2 ). The average number of screws per one vertebra was $1.96 \pm$ 0.09 , with the average number of levels fused being $10.55 \pm$ 1.74 (range 7-15) (Table 1).

\section{Coronal parameters}

The PT curve averaged $26.3^{\circ} \pm 13.3^{\circ}$ and was corrected to $13.6^{\circ} \pm$ $9.3^{\circ}$ postoperatively ( $48.3 \%$ correction) $(p<0.001)$, with maintenance of correction measuring $12.3^{\circ} \pm 9.5^{\circ}$ and $11.8^{\circ} \pm 8.9^{\circ}$ at 2-year and 5 -year follow-up evaluation ( $p=0.818$ and 0.986 ), respectively. The preoperative average MT curve magnitude was $54.0^{\circ} \pm 13.4^{\circ}$, with average curve correction measuring $9.2^{\circ} \pm$ $7.0^{\circ}$ postoperatively $(83.1 \%)(p<0.001), 11.0^{\circ} \pm 7.4^{\circ}$ at 2 -year follow-up ( $p=0.457$ ), and $10.3^{\circ} \pm 7.0^{\circ}$ at 5 -year follow-up ( $p=0.936$ ). The preoperative TL/L curve averaged $35.8^{\circ} \pm 9.4^{\circ}$ and was corrected to $7.1^{\circ} \pm 5.6^{\circ}$ postoperatively $(80.2 \%$ correction $)(p<0.001)$, with maintenance of correction measuring $8.2^{\circ} \pm 7.3^{\circ}$ and $7.4^{\circ} \pm$ $6.5^{\circ}$ at 2 -year and 5 -year follow-up evaluation ( $p=0.810$ and
Table 1. Preoperative Demographic and Radiographic Data

\begin{tabular}{|c|c|c|c|}
\hline Variables & Mean & SD & Range \\
\hline Age (yr) & 15.48 & 3.28 & $10.0-17.8$ \\
\hline Sex, M:F & $26(21 \%): 98(79 \%)$ & & \\
\hline Risser & 2.83 & 1.33 & - \\
\hline Follow-up period (yr) & 6.15 & 1.63 & $5.2-14.8$ \\
\hline Fusion level & 10.55 & 1.74 & $7-15$ \\
\hline Number of screws & 20.71 & 3.57 & $13-28$ \\
\hline Screw density (screw/one vertebra) & 1.96 & 0.09 & $1.6-2.0$ \\
\hline Pelvic incidence $\left({ }^{\circ}\right)$ & 45.8 & 12.0 & $21-78$ \\
\hline \multicolumn{4}{|l|}{ Proximal thoracic } \\
\hline Standing $\left({ }^{\circ}\right)$ & 26.3 & 13.3 & $3-103$ \\
\hline Side-bending $\left({ }^{\circ}\right)$ & 16.5 & 12.0 & $1-95$ \\
\hline Flexibility (\%) & 38.70 & 22.66 & 19-96 \\
\hline \multicolumn{4}{|l|}{ Main thoracic } \\
\hline Standing $\left({ }^{\circ}\right)$ & 54.0 & 13.4 & - \\
\hline Side-bending $\left({ }^{\circ}\right)$ & 26.1 & 14.1 & $1-106$ \\
\hline Flexibility (\%) & 52.75 & 19.32 & $15-98$ \\
\hline \multicolumn{4}{|l|}{ Thoracolumbar/lumbar } \\
\hline Standing $\left(^{\circ}\right)$ & 35.8 & 13.1 & - \\
\hline Side-bending $\left({ }^{\circ}\right)$ & 14.0 & 9.4 & $0-40$ \\
\hline Flexibility (\%) & 61.84 & 20.95 & $0-100$ \\
\hline
\end{tabular}

$\mathrm{M}$, male; F, female; SD, standard deviation.

Table 2. Lenke Curve Type of All Patients

\begin{tabular}{ccc}
\hline Type & Frequency (cases) & Percentage (\%) \\
\hline 1 & 48 & 38.7 \\
2 & 24 & 19.4 \\
3 & 19 & 15.3 \\
4 & 7 & 5.6 \\
5 & 19 & 15.3 \\
6 & 7 & 5.6 \\
\hline
\end{tabular}

0.928), respectively. From the preoperative to the immediate postoperative period, the coronal $\mathrm{C} 7$ plumb line shifted to the left side, and the mean C7-CSVL was significantly different between the two time points ( $p=0.001$ ), with maintenance of correction at the postoperative follow-up. There was no significant difference in LIV-CSVL values at serial follow-up (Table 3, Fig. 1).

\section{Sagittal parameters}

Although there was no statistically significant change in SVA immediately after surgery or during the follow-up duration of 5 years ( $p=0.088,0.617$, and 0.582 ), the $C 7$ sagittal plumb line slightly moved backward during the 5 -year follow-up period. The preoperative TK angle $\left(9.6^{\circ} \pm 7.8^{\circ}\right)$ did not significantly change postoperatively $\left(11.5^{\circ} \pm 6.0^{\circ}, p=0.233\right)$. However, there were gradual increments from the preoperative time point to the 2-year and 5-year follow-up time points of $13.0^{\circ} \pm 7.5^{\circ}$ and $13.0^{\circ} \pm 7.5^{\circ}$ ( $p=0.005$ and 0.004$)$, respectively. The LL showed a similar pattern. The preoperative and postoperative average LL angle measured $46.1^{\circ} \pm 12.0^{\circ}$ and $49.6^{\circ} \pm 12.1^{\circ}$, respectively 
Table 3. Comparison of Coronal Parameters at Preoperative, Immediately Postoperative, 2-Year, and 5-Year Follow-Up Time Points

\begin{tabular}{|c|c|c|c|}
\hline & Mean & SD & $p$ value \\
\hline \multicolumn{4}{|c|}{ Proximal thoracic curve $\left({ }^{\circ}\right)$} \\
\hline Preop. & 26.3 & 13.3 & \\
\hline Imm. postop. & 13.6 & 9.3 & $<0.001^{*}$ \\
\hline Postop. 2-year & 12.3 & 9.5 & 0.818 \\
\hline Postop. 5-year & 11.8 & 8.9 & 0.986 \\
\hline \multicolumn{4}{|c|}{ Main thoracic curve $\left({ }^{\circ}\right)$} \\
\hline Preop. & 54.0 & 13.4 & \\
\hline Imm. postop. & 9.2 & 7.0 & $<0.001^{*}$ \\
\hline Postop. 2-year & 11.0 & 7.4 & 0.457 \\
\hline Postop. 5-year & 10.3 & 7.0 & 0.936 \\
\hline \multicolumn{4}{|c|}{ Thoracolumbar/lumbar curve $\left({ }^{\circ}\right)$} \\
\hline Preop. & 35.8 & 9.4 & \\
\hline Imm. postop. & 7.1 & 5.6 & $<0.001^{*}$ \\
\hline Postop. 2-year & 8.2 & 7.3 & 0.810 \\
\hline Postop. 5-year & 7.4 & 6.5 & 0.928 \\
\hline \multicolumn{4}{|l|}{ C7-CSVL (mm) } \\
\hline Preop. & 1.74 & 13.23 & \\
\hline Imm. postop. & -5.14 & 16.73 & $0.001^{*}$ \\
\hline Postop. 2-year & -7.20 & 11.48 & 0.688 \\
\hline Postop. 5-year & -3.97 & 10.87 & 0.311 \\
\hline \multicolumn{4}{|l|}{ LIV-CSVL (mm) } \\
\hline Preop. & -2.09 & 22.17 & \\
\hline Imm. postop. & -6.39 & 9.59 & 0.150 \\
\hline Postop. 2-year & -6.86 & 10.44 & 0.995 \\
\hline Postop. 5-year & -4.94 & 11.88 & 0.780 \\
\hline
\end{tabular}

SD, standard deviation; Preop., preoperative; Imm. postop., immediately postoperative; CSVL, central sacral vertical line; LIV, last instrumented vertebra. *Statistically significant.
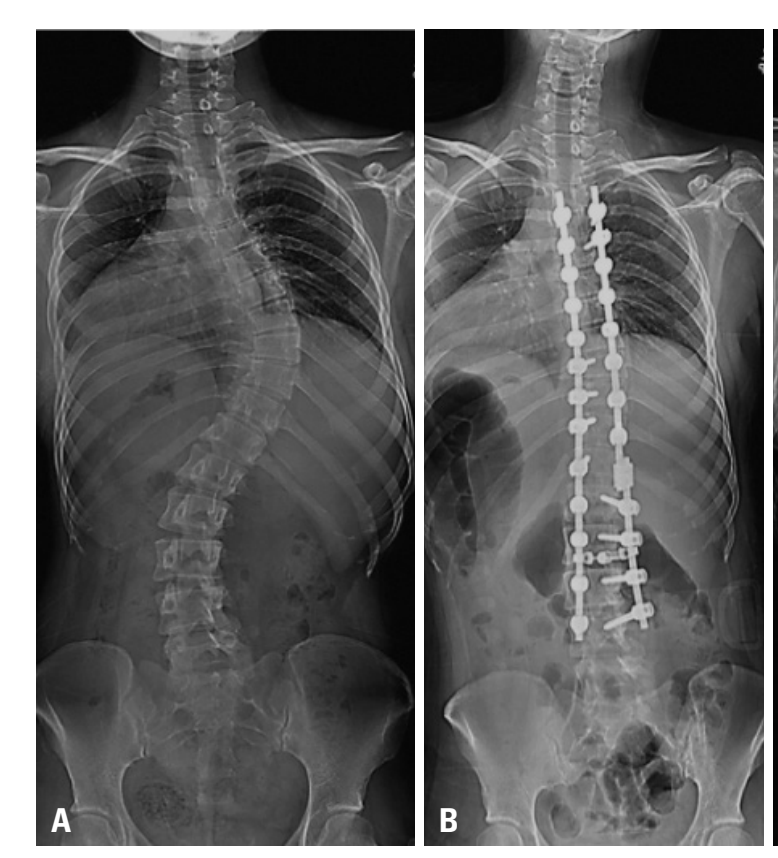

( $p=0.111$ ). However, compared with the preoperative angle, there were statistically significant differences and improvement in the 2-year follow-up average of $52.5^{\circ} \pm 10.5^{\circ}(p<0.001)$ and the 5 -year follow-up average of $53.6^{\circ} \pm 9.9^{\circ}(p<0.001)$ (Table 4, Fig. 2).

\section{Additional radiographic parameters}

The AVT averaged $31.81 \pm 35.20 \mathrm{~mm}$ and was improved to $10.77 \pm 8.72 \mathrm{~mm}$ postoperatively $(p<0.001)$, with maintenance of improvement measuring $10.38 \pm 7.50 \mathrm{~mm}$ and $8.33 \pm 9.02 \mathrm{~mm}$ at 2-year and 5-year follow-up evaluation ( $p=0.999$ and 0.871 ), respectively. The preoperative average AVR measured 1.26 \pm 0.66 , with average improvement of $0.98 \pm 0.49$ postoperatively ( $p=0.003$ ), $0.97 \pm 0.54$ at 2-year follow-up ( $p=0.999)$, and $0.96 \pm$ 0.53 at 5 -year follow-up ( $p=0.999$ ). The preoperative LIVT averaged $19.2^{\circ} \pm 9.3^{\circ}$ and improved to $4.7^{\circ} \pm 3.4^{\circ}$ postoperatively $(p<0.001)$, with maintenance of correction measuring $4.2^{\circ} \pm 3.7^{\circ}$ and $4.5^{\circ} \pm 3.5^{\circ}$ at 2-year and 5-year follow-up ( $p=0.902$ and 0.983 ), respectively. The preoperative average ADW measured $5.6^{\circ} \pm$ $4.0^{\circ}$, with average improvement to $2.1^{\circ} \pm 2.6^{\circ}$ postoperatively $(p<0.001), 2.9^{\circ} \pm 3.2^{\circ}$ at 2 -year follow-up $(p=0.524)$, and $2.8^{\circ} \pm 6.5^{\circ}$ at 5 -year follow-up ( $p=0.998$ ). The right shoulder was higher than the left shoulder before surgery; however, the left shoulder became higher than the right shoulder immediately after surgery. The change in SHD was significantly different. However, as SHD gradually decreased over time, the shoulders became more balanced at final follow-up (Table 5).

\section{Complications}

There were no major complications other than low-grade late
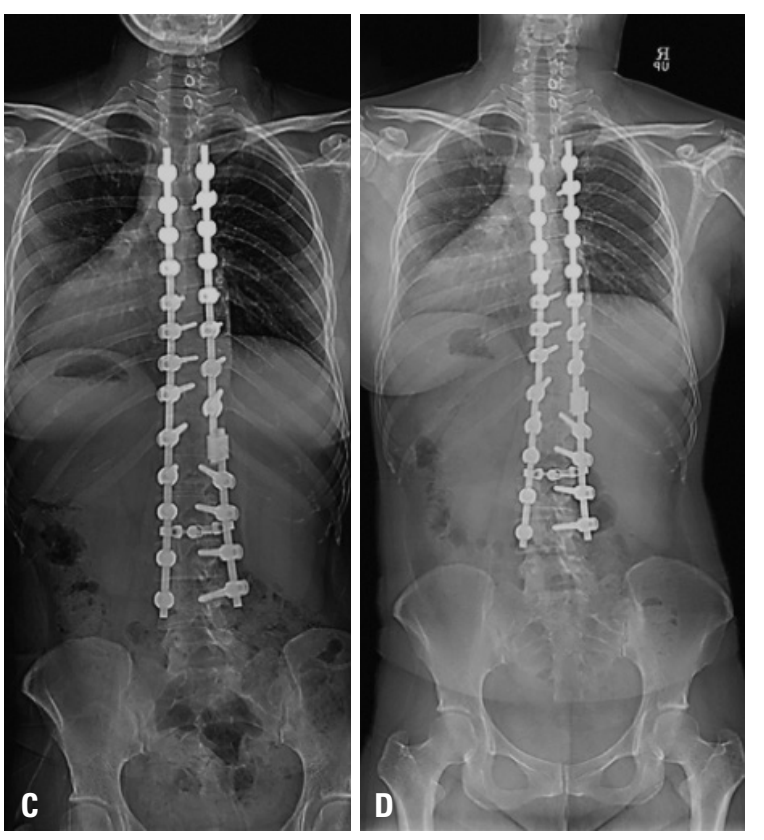

Fig. 1. Whole spine posterior-anterior X-ray series of adolescent idiopathic scoliosis patient. (A) Standing posteroanterior radiograph of a 15-year-old girl showing a $55^{\circ}$ right thoracic curve pre-operatively and a $43^{\circ}$ lumbar curve. (B) Immediate postoperative follow-up radiograph showing correction of the curve with T4-L4 spinal fusion using high-density pedicle screws. (C) Two-year follow-up radiograph showing stable correction. (D) Five-year follow-up radiograph showing that the correction is well maintained. 
implant-associated infections (three cases). All patients successfully recovered after first-generation antibiotic treatment. There were neither acute infections nor neurological complications or pedicle screw-related complications, such as crank

Table 4. Comparison of Sagittal Parameters at Preoperative, Immediately Postoperative, 2-Year, and 5-Year Follow-Up Time Points

\begin{tabular}{lrrrrr}
\hline & Mean & SD & p value & $\begin{array}{c}p \text { value } \\
\text { (preop vs. } \\
\text { 2-yr F/U) }\end{array}$ & $\begin{array}{c}\text { p value } \\
\text { 5-yr F/U) }\end{array}$ \\
\hline Sagittal vertical axis (mm) & & & & & \\
\hline Preop. & 1.84 & 25.28 & & & \\
\hline Imm. postop. & -7.56 & 31.98 & 0.088 & & \\
\hline Postop. 2-year & -7.70 & 26.89 & 0.617 & 0.365 & \\
\hline Postop. 5-year & -7.78 & 29.05 & 0.582 & & 0.451 \\
\hline Thoracic kyphosis $\left(^{\circ}\right)$ & & & & & \\
\hline Preop. & 9.6 & 7.8 & & & \\
\hline Imm. postop. & 11.5 & 6.0 & 0.233 & & \\
\hline Postop. 2-year & 13.0 & 7.5 & 0.467 & $0.005^{*}$ & \\
\hline Postop. 5-year & 13.0 & 7.5 & 1.000 & & $0.004^{*}$ \\
\hline Lumbar lordosis $\left(^{\circ}\right.$ ) & & & & & \\
\hline Preop. & 46.1 & 12.0 & & & \\
\hline Imm. postop. & 49.6 & 12.1 & 0.111 & & \\
\hline Postop. 2-year & 52.5 & 10.5 & 0.269 & $<0.001^{*}$ & \\
\hline Postop. 5-year & 53.6 & 9.9 & 0.882 & & $<0.001^{*}$ \\
\hline
\end{tabular}

SD, standard deviation; Preop., preoperative; Imm. postop., immediately postoperative.

* Statistically significant. shaft phenomena. No patients underwent re-operation until the final follow-up.

\section{DISCUSSION}

Surgical treatment of spinal deformities began with the development of the Harrington device in 1962, followed by Luque and Galveston rods, and sublaminar wires were the mainstay of treatment for several years. ${ }^{17}$ However, these techniques were limited by their inability to correct the deformity of scoliosis three-dimensionally. In the 1980s, Cotrel and Dubousset developed the Cotrel-Dubousset implant and introduced a three-dimensional correction method to restore sagittal alignment through $90^{\circ}$ derotation of a rod. ${ }^{18}$ Suk's thoracic pedicle screw application and direct vertebral rotation technique also contributed substantially to three-plane correction., ${ }^{2,19,20}$

Posterior pedicle screw constructs have currently become the primary surgical strategy for AIS, providing better threedimensional correction and mechanical fixation and lower revision rates than hybrid constructs. ${ }^{8,9,21,22}$ Several studies have shown that pedicle screw-only constructs provide better curve correction than hybrid or hook-only constructs. ${ }^{8,23,24}$ However, controversy remains about the optimal screw density of pedicle screw constructs. ${ }^{25-27}$ Although some authors have described the use of screws on every vertebra in the fusion region, ${ }^{10,28} \mathrm{Min}$, et al. ${ }^{29}$ reported that a comparable correction of $63 \%$ in the MT curve was achieved by using only 9.48 pedicle screws per pa-
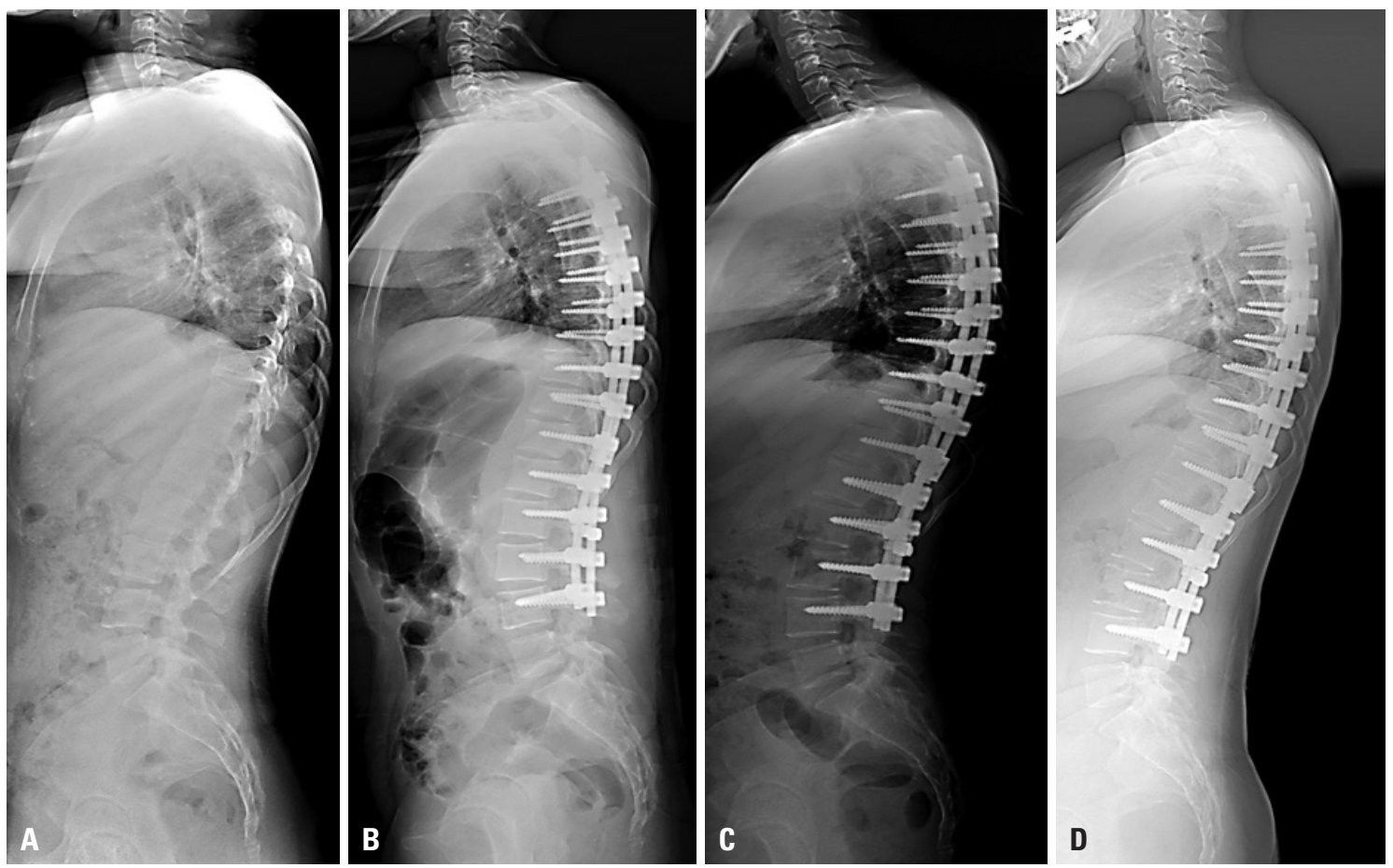

Fig. 2. Whole spine lateral X-ray series of adolescent idiopathic scoliosis patient. (A) Standing lateral radiograph of a 15 -year-old girl with a $55^{\circ}$ thoracic and a $43^{\circ}$ lumbar curve. (B) Immediate postoperative follow-up radiograph after T4-L4 fusion. (C) Two-year follow-up radiograph showing stable correction. (D) Five-year follow-up radiograph showing good maintenance of thoracic kyphosis and lumbar lordosis. 
Table 5. Comparison of Additional Radiographic Parameters at Preoperative, Immediately Postoperative, 2-Year, and 5-Year Follow-Up Time Points

\begin{tabular}{|c|c|c|c|}
\hline & Mean & SD & $p$ value \\
\hline \multicolumn{4}{|c|}{ Apical vertebra translation (mm) } \\
\hline Preop. & 31.81 & 35.20 & \\
\hline Imm. postop. & 10.77 & 8.72 & $<0.001^{*}$ \\
\hline Postop. 2-year & 10.38 & 7.50 & 0.999 \\
\hline Postop. 5-year & 8.33 & 9.02 & 0.871 \\
\hline \multicolumn{4}{|c|}{ Apical vertebra rotation (grade) } \\
\hline Preop. & 1.26 & 0.66 & \\
\hline Imm. postop. & 0.98 & 0.49 & $0.003^{*}$ \\
\hline Postop. 2-year & 0.97 & 0.54 & 0.999 \\
\hline Postop. 5-year & 0.96 & 0.53 & 0.999 \\
\hline \multicolumn{4}{|c|}{ Last instrumented vertebra tilt $\left({ }^{\circ}\right)$} \\
\hline Preop. & 19.2 & 9.3 & \\
\hline Imm. postop. & 4.7 & 3.4 & $<0.001^{*}$ \\
\hline Postop. 2-year & 4.2 & 3.7 & 0.902 \\
\hline Postop. 5-year & 4.5 & 3.5 & 0.983 \\
\hline \multicolumn{4}{|c|}{ Distal adjacent disc wedging $\left({ }^{\circ}\right)$} \\
\hline Preop. & 5.6 & 4.0 & \\
\hline Imm. postop. & 2.1 & 2.6 & $<0.001^{*}$ \\
\hline Postop. 2-year & 2.9 & 3.2 & 0.524 \\
\hline Postop. 5-year & 2.8 & 6.5 & 0.998 \\
\hline \multicolumn{4}{|c|}{ Shoulder height difference $(\mathrm{mm})$} \\
\hline Preop. & 10.58 & 11.99 & \\
\hline Imm. postop. & -14.20 & 14.61 & $<0.001^{*}$ \\
\hline Postop. 2-year & -7.36 & 9.10 & $<0.001^{*}$ \\
\hline Postop. 5-year & -6.22 & 9.81 & 0.893 \\
\hline
\end{tabular}

SD, standard deviation; Preop., preoperative; Imm. postop., immediately postoperative.

*Statistically significant.

tient, meaning an implant density of one screw per vertebra or a 50\% implant density. The correction rate in most studies with skipped pedicle screw fixation was reported to be $<70 \%{ }^{8,9,20} \mathrm{Suk}$, et al. ${ }^{20}$ reported that correction rate of thoracic curve was $69 \%$, with a $3 \%$ loss of correction at recent follow-up, by skipped pedicle screw fixation. Also, Uehara, et al. ${ }^{30}$ reported a MT curve correction rate of $69 \%$ at final follow-up of skip pedicle screw fixation. Meanwhile, however, Yu, et al. ${ }^{31}$ reported a correction rate for a major curve of $72.7 \%$ by an all-screw fixation method. In the current study, an average of 1.96 pedicle screws per one vertebra were placed, providing similar results to $\mathrm{Yu}$, et al., ${ }^{31}$ with excellent coronal curve correction rates: PT, $48.3 \%(p<0.001)$; MT, $83.1 \%$ ( $p<0.001)$; and TL/L curve, $80.2 \%$ ( $p<0.001)$. Through an indirect comparison, we suggest that high-density pedicle screw-only constructs in AIS achieve a high correction rate; however, our study does not provide a definite answer because of the absence of a control group.

In this study, coronal profiles remained stable at the final follow-up with no significant change, compared with the immediate postoperative period. Larson, et al. ${ }^{27}$ also document- ed improved percentage correction of the major coronal curve in a high-screw density cohort. Additionally, AVT, AVR, LIVT, ADW, and SHD were significantly improved and well maintained during the follow-up period. In particular, the left shoulder tended to become higher than the right shoulder in the immediate postoperative period. This suggests that high-density pedicle screw constructs may allow for a greater correction force to be applied without screw pull-out at the apical vertebra. The correcting force comes from rod rotation maneuver not from the pedicle screw construct. However, SHD was gradually restored at the 2-year and 5-year follow-up periods.

Restoration of TK is imperative in AIS surgery because rotational deformity results in hypokyphosis in most patients. The effect of screw density on TK restoration has been reported in a few studies, with controversial results. ${ }^{9,27,28,32,33}$ Larson, et al. ${ }^{27}$ and Lonner, et al. ${ }^{32}$ reported that an increasing number of screws was related to decreasing kyphosis at the final follow-up. However, Liu, et al. ${ }^{33}$ documented that a high screw density provided better TK restoration than a low pedicle screw density. In the current study, the TK angle slightly increased by approximately $2^{\circ}$ immediately after surgery, and TK was gradually restored to $3^{\circ}$ at the 2 -year follow-up and to $4^{\circ}$ at the 5 -year follow-up. This gradual increase in TK angle may be due to measurement errors, minimal screw loosening, or overall settling mechanism. Although the change in TK angle immediately after surgery was not statistically significant, we believe that TK was restored and maintained well because of the greater correction power of high-density pedicle screw constructs. The LL followed a similar pattern. The increase in LL angle was statistically significant at the 2-year and 5-year follow-up periods. Whereas most of the thoracic curves would have been fused, the lumbar curve might not have been fused, or even if it was fused, the fusion did not reach below the L3 level to save motion segments. However, we had applied pedicle screws up to L4 for increasing correction power in some cases. Therefore, there may have been a change in the remaining lumbar segments, resulting in improvement of LL over time after surgery.

Our study has several limitations. It was not a prospective study, and we could not compare constructs with different screw densities. Also, we did not consider potential cofounders, such as Risser stage, that might have an effect on the correction rate afforded by the high-density pedicle screw constructs. Also, there is the possibility of bias by including Lenke 5 in the results. There have already been extensive reports on the safety and efficacy of high-density pedicle screw constructs for the treatment of AIS. However, our patients had very high screw densities because we always tried to place screws in every pedicle. This is the most substantial point of difference compared with previous reports. Notwithstanding, to the best of our knowledge, this is the largest consecutive series involving Asian patients with AIS who were treated with high-density pedicle screws and had a minimum of 5-year follow-up. Although functional scoring of patients, such as Scoliosis Research Society 
scores, is important in reporting surgical results, clinical data assessments were not available because we have only recently started to implement functional evaluation. Further research is required with clinical data and long-term follow-up to validate the advantages of high-density screw constructs in AIS surgery.

In conclusion, we obtained excellent correction rates of

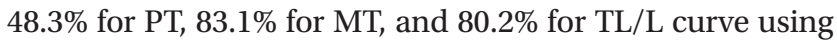
high-density pedicle screw-only constructs in AIS, with no significant loss of correction at final follow-up.

\section{AUTHOR CONTRIBUTIONS}

Conceptualization: Chang Ju Hwang and Jong-Min Baik. Data curation: Chang Ju Hwang, Jong-Min Baik, and So Jeong Yoon. Formal analysis: Jong-Min Baik and Jae Hwan Cho. Investigation: all authors. Methodology: all authors. Project administration: all authors. Resources: all authors. Software: all authors. Supervision: Chang Ju Hwang and Choon Sung Lee. Validation: Chang Ju Hwang. Visualization: Jong-Min Baik. Writing_original draft: Jong-Min Baik. Writing-review \& editing: Jong-Min Baik and Chang Ju Hwang. Approval of final manuscript: all authors.

\section{ORCID iDs}

$\begin{array}{ll}\text { Chang Ju Hwang } & \text { https://orcid.org/0000-0001-5666-3135 } \\ \text { Jong-Min Baik } & \text { https://orcid.org/0000-0002-6646-2449 } \\ \text { Jae Hwan Cho } & \text { https://orcid.org/0000-0002-1178-9778 } \\ \text { So Jeong Yoon } & \text { https://orcid.org/0000-0002-3972-7288 } \\ \text { Dong-Ho Lee } & \text { https://orcid.org/0000-0003-3704-6355 } \\ \text { Choon Sung Lee } & \text { https://orcid.org/0000-0002-3263-9410 }\end{array}$

\section{REFERENCES}

1. Kepler CK, Meredith DS, Green DW, Widmann RF. Long-term outcomes after posterior spine fusion for adolescent idiopathic scoliosis. Curr Opin Pediatr 2012;24:68-75.

2. Suk SI, Lee CK, Kim WJ, Chung YJ, Park YB. Segmental pedicle screw fixation in the treatment of thoracic idiopathic scoliosis. Spine (Phila Pa 1976) 1995;20:1399-405.

3. Shufflebarger HL, Geck MJ, Clark CE. The posterior approach for lumbar and thoracolumbar adolescent idiopathic scoliosis: posterior shortening and pedicle screws. Spine (Phila Pa 1976) 2004;29: 269-76.

4. Hee HT, Yu ZR, Wong HK. Comparison of segmental pedicle screw instrumentation versus anterior instrumentation in adolescent idiopathic thoracolumbar and lumbar scoliosis. Spine (Phila Pa 1976) 2007;32:1533-42.

5. Li M, Ni J, Fang X, Liu H, Zhu X, He S, et al. Comparison of selective anterior versus posterior screw instrumentation in Lenke5C adolescent idiopathic scoliosis. Spine 2009;34:1162-6.

6. Wang Y, Fei Q, Qiu G, Lee CI, Shen J, Zhang J, et al. Anterior spinal fusion versus posterior spinal fusion for moderate lumbar/thoracolumbar adolescent idiopathic scoliosis: a prospective study. Spine (Phila Pa 1976) 2008;33:2166-72.

7. Papin P, Labelle H, Delorme S, Aubin CE, de Guise JA, Dansereau J. Long-term three-dimensional changes of the spine after posterior spinal instrumentation and fusion in adolescent idiopathic scoliosis. Eur Spine J 1999;8:16-21.

8. Crawford AH, Lykissas MG, Gao X, Eismann E, Anadio J. All-pedicle screw versus hybrid instrumentation in adolescent idiopathic scoliosis surgery: a comparative radiographical study with a minimum 2-year follow-up. Spine (Phila Pa 1976) 2013;38:1199-208.

9. Hwang SW, Samdani AF, Marks M, Bastrom T, Garg H, Lonner B, et al. Five-year clinical and radiographic outcomes using pedicle screw only constructs in the treatment of adolescent idiopathic scoliosis. Eur Spine J 2013;22:1292-9.

10. Uehara M, Takahashi J, Ikegami S, Oba H, Kuraishi S, Futatsugi T, et al. Determination of optimal screw number based on correction angle for main thoracic curve in adolescent idiopathic scoliosis. J Orthop Sci 2019;24:415-9.

11. Lenke LG, Betz RR, Clements D, Merola A, Haher T, Lowe T, et al. Curve prevalence of a new classification of operative adolescent idiopathic scoliosis: does classification correlate with treatment? Spine (Phila Pa 1976) 2002;27:604-11.

12. Nash CL Jr, Moe JH. A study of vertebral rotation. J Bone Joint Surg Am 1969;51:223-9.

13. Lee CS, Kim MJ, Ahn YJ, Kim YT, Jeong KI, Lee DH. Thoracic pedicle screw insertion in scoliosis using posteroanterior C-arm rotation method. J Spinal Disord Tech 2007;20:66-71.

14. King HA, Moe JH, Bradford DS, Winter RB. The selection of fusion levels in thoracic idiopathic scoliosis. J Bone Joint Surg Am 1983; 65:1302-13.

15. Lenke LG, Edwards CC 2nd, Bridwell KH. The Lenke classification of adolescent idiopathic scoliosis: how it organizes curve patterns as a template to perform selective fusions of the spine. Spine (Phila Pa 1976) 2003;28:S199-207.

16. Lee CS, Hwang CJ, Lee DH, Cho JH. Five major controversial issues about fusion level selection in corrective surgery for adolescent idiopathic scoliosis: a narrative review. Spine J 2017;17:103344.

17. Cochran T, Irstam L, Nachemson A. Long-term anatomic and functional changes in patients with adolescent idiopathic scoliosis treated by Harrington rod fusion. Spine (Phila Pa 1976) 1983;8: 576-84.

18. Wood KB, Transfeldt EE, Ogilvie JW, Schendel MJ, Bradford DS. Rotational changes of the vertebral-pelvic axis following CotrelDubousset instrumentation. Spine (Phila Pa 1976) 1991;16(8 Suppl): S404-8.

19. Suk SI, Kim JH, Kim SS, Lim DJ. Pedicle screw instrumentation in adolescent idiopathic scoliosis (AIS). Eur Spine J 2012;21:13-22.

20. Suk SI, Lee SM, Chung ER, Kim JH, Kim SS. Selective thoracic fusion with segmental pedicle screw fixation in the treatment of thoracic idiopathic scoliosis: more than 5-year follow-up. Spine (Phila Pa 1976) 2005;30:1602-9.

21. Kuklo TR, Potter BK, Lenke LG, Polly DW Jr, Sides B, Bridwell KH. Surgical revision rates of hooks versus hybrid versus screws versus combined anteroposterior spinal fusion for adolescent idiopathic scoliosis. Spine (Phila Pa 1976) 2007;32:2258-64.

22. Samdani AF, Belin EJ, Bennett JT, Pahys JM, Marks MC, Miyanji F, et al. Unplanned return to the operating room in patients with adolescent idiopathic scoliosis: are we doing better with pedicle screws? Spine (Phila Pa 1976) 2013;38:1842-7.

23. Cheng I, Kim Y, Gupta MC, Bridwell KH, Hurford RK, Lee SS, et al. Apical sublaminar wires versus pedicle screws--which provides better results for surgical correction of adolescent idiopathic scoliosis? Spine (Phila Pa 1976) 2005;30:2104-12.

24. Vora V, Crawford A, Babekhir N, Boachie-Adjei O, Lenke L, Peskin $\mathrm{M}$, et al. A pedicle screw construct gives an enhanced posterior correction of adolescent idiopathic scoliosis when compared with other constructs: myth or reality. Spine (Phila Pa 1976) 2007;32: 1869-74.

25. Clements DH, Betz RR, Newton PO, Rohmiller M, Marks MC, Bastrom T. Correlation of scoliosis curve correction with the number 
and type of fixation anchors. Spine (Phila Pa 1976) 2009;34:2147-50.

26. Hwang CJ, Lee CK, Chang BS, Kim MS, Yeom JS, Choi JM. Minimum 5-year follow-up results of skipped pedicle screw fixation for flexible idiopathic scoliosis. J Neurosurg Spine 2011;15:146-50.

27. Larson AN, Polly DW Jr, Diamond B, Ledonio C, Richards BS 3rd, Emans JB, et al. Does higher anchor density result in increased curve correction and improved clinical outcomes in adolescent idiopathic scoliosis? Spine (Phila Pa 1976) 2014;39:571-8.

28. Lehman RA Jr, Lenke LG, Keeler KA, Kim YJ, Buchowski JM, Cheh $\mathrm{G}$, et al. Operative treatment of adolescent idiopathic scoliosis with posterior pedicle screw-only constructs: minimum three-year follow-up of one hundred fourteen cases. Spine (Phila Pa 1976) 2008; 33:1598-604.

29. Min K, Sdzuy C, Farshad M. Posterior correction of thoracic adolescent idiopathic scoliosis with pedicle screw instrumentation: results of 48 patients with minimal 10-year follow-up. Eur Spine J 2013;22:345-54.

30. Uehara M, Takahashi J, Ikegami S, Kuraishi S, Futatsugi T, Oba H, et al. Mid-term results of computer-assisted skip pedicle screw fixation for patients with Lenke type 1 and 2 adolescent idiopathic scoliosis: a minimum five-year follow-up study. J Orthop Sci 2018;23: 248-52.

31. Yu CH, Chen PQ, Ma SC, Pan CH. Segmental correction of adolescent idiopathic scoliosis by all-screw fixation method in adolescents and young adults: minimum 5 years follow-up with SF36 questionnaire. Scoliosis 2012;7:5.

32. Lonner BS, Lazar-Antman MA, Sponseller PD, Shah SA, Newton $\mathrm{PO}$, Betz R, et al. Multivariate analysis of factors associated with kyphosis maintenance in adolescent idiopathic scoliosis. Spine (Phila Pa 1976) 2012;37:1297-302.

33. Liu H, Li Z, Li S, Zhang K, Yang H, Wang J, et al. Main thoracic curve adolescent idiopathic scoliosis: association of higher rod stiffness and concave-side pedicle screw density with improvement in sagittal thoracic kyphosis restoration. J Neurosurg Spine 2015;22:259-66. 